\title{
Arthroscopy surgery versus shock wave therapy for chronic calcifying tendinitis of the shoulder
}

\author{
Enrico Rebuzzi · Nicolò Coletti · Stefano Schiavetti · \\ Fernando Giusto
}

Received: 30 December 2007/ Accepted: 28 June 2008/Published online: 8 August 2008

(C) Springer-Verlag 2008

\begin{abstract}
Background There are several treatment modalities for calcifying tendinitis of the shoulder. If the pain becomes chronic after several months of conservative treatment, open or arthroscopic removal is usually recommended. Recently, extracorporeal shock wave therapy has shown encouraging results in treating calcific deposits.

Materials and methods We report a retrospective study to compare the outcome after arthroscopic extirpation (group I, 22 cases) with the effect of low extracorporeal shock wave therapy (group II, 24 cases) in patients with a chronic homogeneous calcific deposit in the supraspinatus tendon. Patients included in the study had undergone unsuccessful conservative therapy in the previous six months with no evidence of subacromial impingement of the rotator cuff independent of the calcium deposit or rupture of the rotator cuff detected by sonography or magnetic resonance imaging. AP and LL radiographies were performed for all of the patients at least one week before the treatment and 24 months after the treatment. To keep the possibility of spontaneous resorption low, the deposit had to be sharply outlined and densely structured on the radiograph (types I and II in the Gärtner classification). In group II, the patients underwent an average of three treatment sessions of
\end{abstract}

Each author certifies that his or her ethical board institution has approved or waived approval for the human protocol for this investigation and that all the investigation were conducted in conformity with the Declaration of Helsinki. All the patients gave informed consent.

E. Rebuzzi · N. Coletti · S. Schiavetti - F. Giusto

Operative Unit of Orthopaedics, Oderzo Hospital, Treviso, Italy

E. Rebuzzi $(\bowtie)$

via Garibaldi 73, 33080 Cecchini di Pasiano, Pordenone, Italy

e-mail: enricorebuzzi@alice.it extracorporeal shock waves therapy with 1,500 impulses/ session of $0.10-0.13 \mathrm{~mJ} / \mathrm{mm}^{2}$.

Results Preoperative symptoms $(P=0.09)$, sex $(P=0.17)$, operated $(P=0.11)$ and dominant $(P=0.33)$ limbs, and age $(P=0.99)$ of the two groups did not show a significative difference between groups. According to the University of California Los Angeles (UCLA) rating system, the mean score in group I improved from $9.36( \pm 5.2)$ to $30.3( \pm 7.62)$ points after 24 months, with $81.81 \%$ reporting good or excellent results $(P<0.001)$. In group II the mean score after 24 months rose from $12.38( \pm 6.5)$ to $28.13( \pm 9.34)$ points, with $70.83 \%$ reporting good or excellent results $(P<0.001)$. Radiologically, after two years of follow up, there was no calcific deposit in $86.35 \%$ $(P<0.001)$ of the patients of group I and in $58.33 \%$ $(P<0.001)$ of the patients of group II. According to the UCLA scores, there was no significant difference between the groups at two years of follow-up $(P=0.38)$.

Conclusions We conclude that shock wave therapy is equivalent to arthroscopy, and so shock wave therapy should be preferred because of its noninvasiveness.

Keywords Arthroscopy - Shock waves - Calcification · Tendinitis $\cdot$ Shoulder

\section{Introduction}

Numerous treatments have been advocated for calcific tendinitis. The initial treatment is usually conservative, consisting of a sling, a nonsteroid medicine, and a subacromial bursal corticosteroid injection. In most cases, clinical symptoms will resolve spontaneously in 7-10 days, whereas the deposit may persist on radiographs. In cases with prolonged symptoms, good results have been reported 
with needling $[6,11,17,23]$, open $[13,31,40]$ or arthroscopic $[1,5,12,19]$ calcium excision.

The arthroscopic procedure has proven to be successful in $50-82 \%$ of the cases $[1,7,19]$. All authors have stressed the importance of complete removal of the calcific deposit. Subacromial decompression was thought to be of minor importance. Cases of postoperative capsulitis have been reported [36].

Recently, extracorporeal shock wave therapy (ESWT) has shown good results in the treatment of calcific deposits. Different studies have shown that relief from pain and radiological disintegration of calcification are better obtained by using a high dose density and administering anesthesia. Long-term follow-up and the evaluation of intraoperative findings after ESWT point to a low complication rate $[2,3,8,14,16,25]$. ESWT focuses acoustic waves in order to induce fragmentation and deposit resorption. High-energy shock waves are expected to exert a direct mechanical disintegration effect on calcareous deposits in the rotator cuff tendon. Low-energy ESWT is regarded as a form of hyperstimulation analgesia.

The goal of this study was to compare the efficiency of arthroscopic surgery and low extracorporeal shock wave application in patients with chronic symptomatic calcifying tendinitis of the supraspinatus tendon.

\section{Materials and methods}

Fifty patients with chronic calcific tendinitis of the supraspinatus were treated between January 2000 and January 2005. None of the patients included had responded to at least six months of conservative treatment and none presented acromial spurs or acromioclavicular osteophytes on anteroposterior radiographs or rotator cuff tears. All of the patients had clinical examinations, anteroposterior radiographs, acromial outlet views, sonography or magnetic resonance imaging. The calcareous deposit was at least $10 \mathrm{~mm}$ in diameter. The deposit was homogeneous and had well-defined borders (type I in the Gärtner classification) [6]. The patients were informed about arthroscopic surgical removal of the deposit and about ESWT as a nonsurgical alternative. All of the patients asked their health insurance companies for reimbursement of the ESWT. In 26 cases the reimbursement was offered. The others had to undergo surgery. Four of the patients dropped out during the study, leaving 46 patients. It was not possible to contact two patients from group I, and two patients from group II underwent a surgical procedure in another hospital.

Group I consisted of 22 patients. Preoperative data are shown in Table 1. The surgical technique was in accordance with that described by Snyder and Gartsman [7, 36].
Table 1 Before-treatment data

\begin{tabular}{|c|c|c|c|}
\hline & $\begin{array}{l}\text { Group I arthroscopy } \\
\text { ( } 22 \text { cases) }\end{array}$ & $\begin{array}{l}\text { Group II ESWT } \\
\text { ( } 24 \text { cases })\end{array}$ & $\begin{array}{l}P \text {-value } \\
\text { (group } \\
\text { I vs. II) }\end{array}$ \\
\hline $\operatorname{Sex}(M / F)$ & $5 / 17$ & $10 / 14$ & 0.17 \\
\hline $\begin{array}{l}\text { Side R/L } \\
\quad \text { (dominant) }\end{array}$ & $15(14) / 7(3)$ & $21(20) / 3(1)$ & $0.11(0.33)$ \\
\hline Age (mean) & $48.9( \pm 9.5)$ & $48.8( \pm 15.3)$ & 0.99 \\
\hline Follow up & 24 months & 24 months & \\
\hline
\end{tabular}

${ }^{a} P$-value, analysis of variance

The patients were placed in a beach chair position under general anesthesia. We established a routine posterior glenohumeral joint portal and performed a glenohumeral inspection. An increased vascularity of the rotator cuff usually corresponds to the location of the calcium deposit. At this point we inserted a needle through the hyperemic area. We observed the needle on the articular side as it passed through the cuff. Occasionally there was a small amount of calcium lodged in the tip of the needle. An absorbable No. 2 monofilament suture was passed through the needle to mark the position of the deposit in the subacromial space. Then we inserted the arthroscope into the subacromial space through the posterior portal and established a lateral subacromial portal. We then identified the suture and usually performed a bursectomy. When the tendon from articular side appeared normal we inserted a spinal needle from the lateral side and punctured the tendon in multiple areas of the suspected lesion until when calcium deposit leaked into the subacromial space. Once the calcium deposit was identified we used a motorized shaver from the lateral portal to remove the calcific deposit. Upon completion of the debridement, when the rotator cuff defect was greater than $1 \mathrm{~cm}$ we performed a side-to-side repair with the arthroscope in the lateral portal and a cannula $(7 \mathrm{~mm} \times 20 \mathrm{~mm})$ in the anterior portal, inserting a crescent-shaped Spectrum suture passer (Linvatec, Largo, FL, USA) loaded with a No. 1 PDS suture (Fig. 1). After the operation, the arm was supported by a sling and pendulum exercises were started the day after surgery before discharge. After three days, assisted active motion was carried out with no limitation on the range of motion for 3-4 weeks. Each patient underwent an average of 18 $( \pm 9.3)$ various rehabilitation settings.

Group II consisted of 24 patients. Preoperative data are shown in Table 1. Patients were placed in sitting position, and the shock wave device was focused on the treatment area. We utilized an electrohydraulic shock wave generator (Reflectron, High Medical Technologies AG, Lengwil, Switzerland). This system is equipped with a special therapeutic head (reflectrode) with an endurance of 50,000 shocks, and is available in three models characterized by 

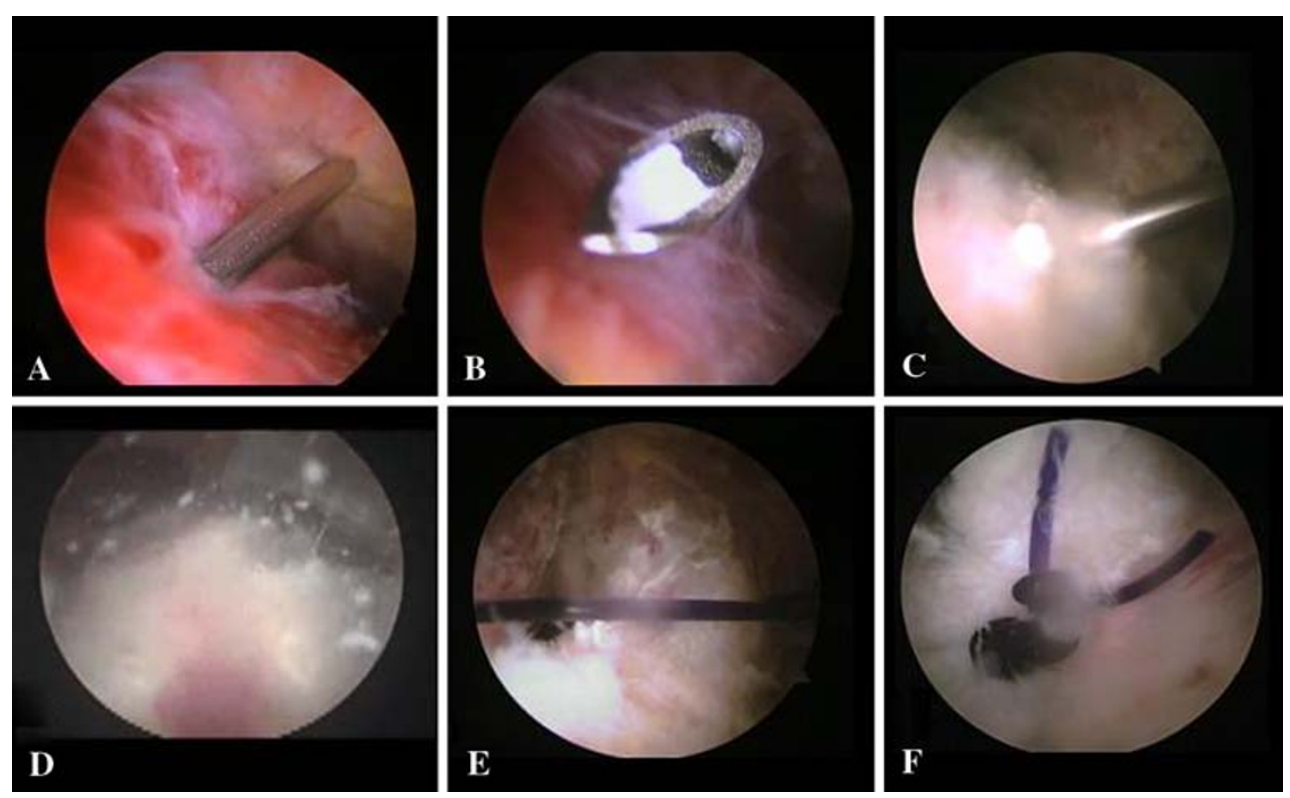

Fig. 1 In the right shoulder: a insertion through a lateral subacromial portal of a spinal needle into the suspected lesion; b the presence of calcium lodged in the tip of the needle; $\mathbf{c}$ puncture of the tendon; and $\mathbf{d}$ leakage of the calcium deposit; $\mathbf{e}, \mathbf{f}$ side-to-side repair of the defect

three different ranges of penetration depth, from the minimum (E1) to the maximum (E9) energy level (from 0 to $29 \mathrm{~mm}$, from 12.5 to $44 \mathrm{~mm}$ and from 27.5 to $59 \mathrm{~mm}$ ), in order best to match the depth of each pathology. Furthermore, the system is provided with an ultrasound unit and a special probe for the accurate localization of the lesion. The arm was abducted and the elbow flexed at $90^{\circ}$. Each patient underwent an average of three treatment sessions $( \pm 0.8)$, with 1,500 shocks delivered per session and a twoweek interval. Shocks were delivered at $240 / \mathrm{min}$ and the energy flux density was incrementally increased from 0.10 to $0.13 \mathrm{~mJ} / \mathrm{mm}^{2}$ with a reflectrode that provides $20 \mathrm{~mm}$ of penetration depth. Regional anesthesia was not used, even though all of the patients complained of moderate pain during the treatment. The VAS score for ESWT treatment was 50 points $( \pm 10)$. Common ultrasound gel was used as the medium between the reflectrode and skin. Cold therapy was allowed after the procedure. Normal activities began the day after, and none of the patients underwent rehabilitation treatments.

Follow-up evaluations were performed independent of the treating orthopedic surgeon at 12 and 24 months. All patients were evaluated before treatment and at the 24-month follow-up using the UCLA rating for pain and function. According to this scheme, pain and function are rated on a score of $1-10$ points, with 1 point being the worst score and 10 points being the best score. The range of active forward flexion and the patient satisfaction were scored from 0 to 5 points. Strength was graded from 0 to 5 points, with 5 points representing normal strength
(0-5 system). The strength of the supraspinatus was measured manually with the arm at $90^{\circ}$ of abduction and $30^{\circ}$ of horizontal flexion (elevation in the scapular plane). If $90^{\circ}$ of elevation was not possible, then strength was measured with the shoulder at maximum elevation. The strengths of external and internal rotation were measured with the arm at the side in a neutral position. The maximum score possible was 35 points (33-35 points, excellent; 29-33 points, good; $<29$, poor). Anteroposterior and outlet views of the acromion were obtained before both treatments and at 24 months of follow-up.

The changes in the UCLA score and in its variables were analyzed with the paired Student's $t$-test, with differences between groups were analyzed using an analysis of variance test. $P<0.05$ was considered statistically significant.

\section{Results}

At a minimum of 24 months of follow-up, 22 patients in group I and 24 patients in group II were examined. The full UCLA score data are shown in Table 2. Comparisons of both groups regarding point values and regarding excellent or good outcomes showed no significant differences at 24 months $(P=0.38)$. According to the UCLA score, the mean score in group I improved from $9.3( \pm 5.2)$ to 30.3 $( \pm 7.62)$ points, with $81.81 \%$ reporting good or excellent results $(P<0.001)$. In group II, the mean score after treatment rose from $12.38( \pm 6.5)$ to $28.13( \pm 9.34)$ points, with $70.83 \%$ reporting good or excellent results 
Table 2 Correlations between the UCLA parameters and scores before and after arthroscopy and ESWT

\begin{tabular}{|c|c|c|c|c|c|c|}
\hline & \multicolumn{6}{|c|}{ UCLA score } \\
\hline & Pain & Function & ROM mean $( \pm \mathrm{SD})$ & Strength & Satisfaction & Total \\
\hline \multicolumn{7}{|c|}{ Group I arthroscopy (22 cases) } \\
\hline Before treatment & $1.7(1.1)$ & $3.1(2.4)$ & $2.0(1.5)$ & $2.4(1.2)$ & 0 & $9.3(5.2)$ \\
\hline After treatment & $8.1(2.7)$ & $8.5(2.6)$ & $4.5(0.8)$ & $4.6(0.7)$ & $4.3(1.7)$ & $30.3(7.6)$ \\
\hline$P$-value ${ }^{\mathrm{a}}$ & $<0.001$ & $<0.001$ & $<0.001$ & $<0.001$ & $<0.001$ & $<0.001$ \\
\hline \multicolumn{7}{|l|}{ Group II ESWT } \\
\hline Before treatment & $2.4(1.7)$ & $4.1(2.9)$ & $2.5(1.4)$ & $3.2(1.3)$ & 0 & $12.3(6.5)$ \\
\hline After treatment & $7.3(2.8)$ & $8.4(2.6)$ & $4.3(1.2)$ & $4.5(0.9)$ & $3.5(2.3)$ & $28.1(9.3)$ \\
\hline$P$-value ${ }^{\mathrm{a}}$ & $<0.001$ & $<0.001$ & $<0.001$ & $<0.001$ & $<0.001$ & $<0.001$ \\
\hline \multicolumn{7}{|c|}{$P$-value ${ }^{\mathrm{b}}$ (group I vs. II) } \\
\hline Before treatment & 0.10 & 0.21 & 0.24 & 0.03 & - & 0.09 \\
\hline After treatment & 0.33 & 0.89 & 0.51 & 0.67 & 0.19 & 0.38 \\
\hline
\end{tabular}

${ }^{a} P$-value, paired Student's $t$-test

b $P$-value, analysis of variance

$(P<0.001)$. After being discharged from the hospital, the patients in group I returned to work at an average of $8 \pm 3$ weeks. Patients in group II did not stop their activities.

At 24 months, 18 patients in group I reported excellent or good results $(81.81 \%)$, with complete or partial resorption of the calcification. In group II, at the same follow-up, 17 patients reported excellent or good results $(70.83 \%)$. Fourteen of these had complete or partial resorption of the calcification and three had no change in the calcification. None of the fair results for the two groups reported a change in the calcific deposit (Table 3; Fig. 2). Patients in group I remained in the hospital for $24 \mathrm{~h}$. No complications were observed in either group. At 24 months, 17 patients in group I reported complete relief from pain, three reported moderate relief, and two reported no reduction in pain. Sixteen patients in group II reported complete relief from pain, six moderate relief and two no reduction in pain.

With regard to the poor results in group I, one patient had an intra-articular lesion of the supraspinatus, and the other underwent an anterolateral acromioplasty. In group II, both of the patients had a homogeneous calcific deposit that had only partially disappeared at 24 months.

\section{Discussion}

The cause of calcifying tendinitis of the shoulder is unknown. Uthoff found that the affected tendon was transformed into fibrocartilage. This phase was followed by a calcification phase and then by a resorptive phase in which the deposit is surrounded by phagocytosing cells and a proliferation of vascular channels. This author found a significant correlation between severe pain and histological signs of resorption [37].
Table 3 Correlation between the outcomes obtained according to the UCLA system and the radiological changes after arthroscopy and ESWT

\begin{tabular}{|c|c|c|}
\hline & \multicolumn{2}{|c|}{ No. of cases $(\%)$} \\
\hline & Excellent/good & Poor \\
\hline \multicolumn{3}{|c|}{ Group I arthroscopy (22 cases) } \\
\hline Complete resorption & $15(68.18)$ & - \\
\hline Partial resorption & $3(13.63)$ & $1(4.54)$ \\
\hline No change & - & $3(13.63)$ \\
\hline \multicolumn{3}{|c|}{$P$-value ${ }^{\mathrm{a}}$ before and after the treatment $=0.001$} \\
\hline \multicolumn{3}{|l|}{ Group II ESWT ( 24 cases) } \\
\hline Complete resorption & $12(50.0)$ & - \\
\hline Partial resorption & $2(8.33)$ & - \\
\hline No change & $3(12.5)$ & $7(29.16)$ \\
\hline \multicolumn{3}{|c|}{$P$-value ${ }^{\mathrm{a}}$ before and after the treatment $=0.001$} \\
\hline$P$-value ${ }^{\mathrm{b}}$ (group I vs. II) & 0.955 & 0.79 \\
\hline
\end{tabular}

The arthroscopic procedure was developed, with success, to avoid damage from open surgery. Ellman and Gartsman [5] reported on a multicenter study of 131 patients treated with an arthroscopic technique. The average Constant functional score was 69.4 out of a possible 75. There was no correlation with patient age, size of the calcification or duration of the symptoms.

There is controversy with regard to the improvement in results with an associated acromioplasty [5, 12, 21, 24, 32]. However, the greatest care must be taken in the surgical indication for this pathology because of a high rate of spontaneous resorption [19].

The shock or sound waves used medically are singleimpulse acoustic waves generated in water by an 


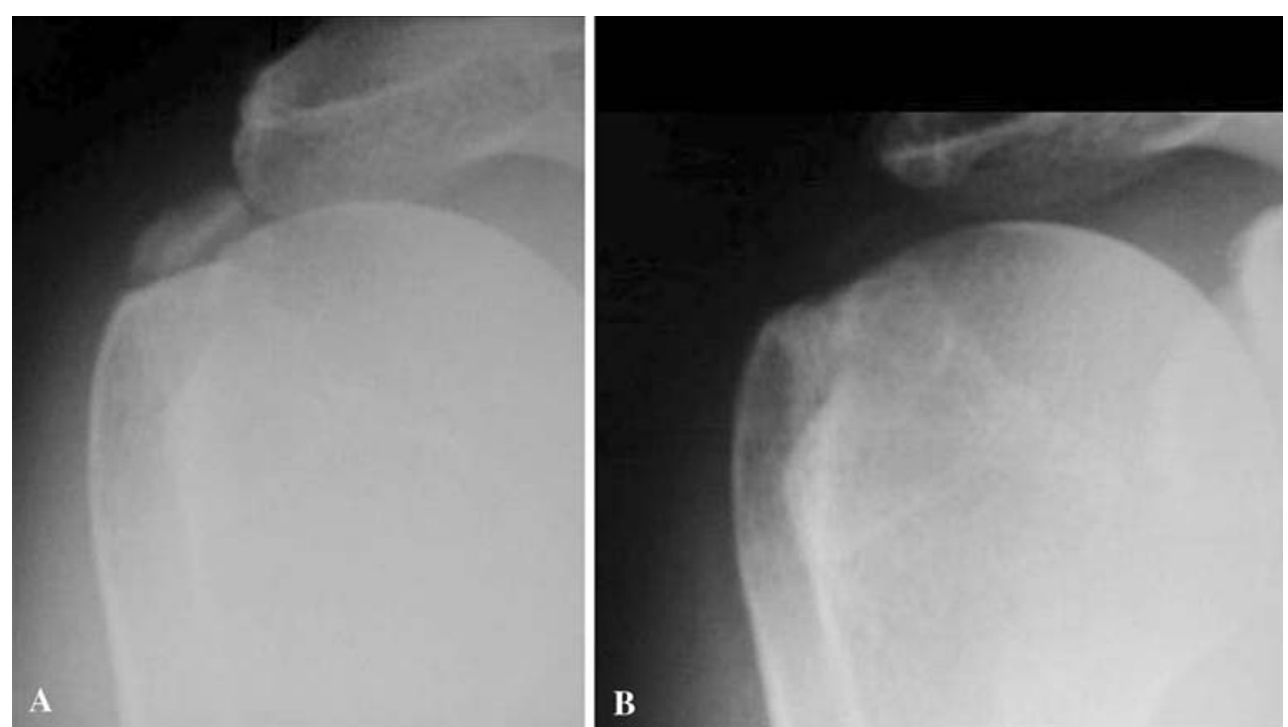

Fig. 2 Anteroposterior radiograph of the right shoulder showing a homogeneous calcification of the supraspinatus before ESWT treatment (a), which was not visible after treatment at 2 years of follow-up (b)

electrohydraulic, electromagnetic or piezoelectric source. They can act in liquid or solid bodies. For shock-wave therapy, the waves are focused by an acoustic lens or reflector system to a focal point inside the target tissue. Their physical characteristics are such that absorption in biological tissue is quite low. For medical use, shock waves of approximately 0.001$0.4 \mathrm{~mJ} / \mathrm{mm}^{2}$ are applied. It is useful to differentiate lowenergy shock waves, with an energy at the focal point of less than $0.1 \mathrm{~mJ} / \mathrm{mm}^{2}$, from high-energy waves, with an energy of $0.2-0.4 \mathrm{~mJ} / \mathrm{mm}^{2}$ [15]. High-energy waves have a physical impact on kidney stones, gallstones and bony tissue, but their side effects include intramuscular hematoma and hypervascularization with local cellular proliferation in soft tissue [28, 35]. By contrast, the therapeutic effect of low-energy shock waves on painful enthesopathies seems to be based on neurophysiological mechanisms [26, 27]. However, the value of shock-wave treatment has been proven in the treatment of patients with fracture nonunion, with a $75 \%$ success rate achieved [34, 38], and there was a positive effect in patients with tennis elbow, painful heel and tendinitis of the shoulder $[3,10,14,16,18,25,26,39]$. The mechanism of the therapeutic effect of ESWT on shoulder calcification is not certain. The hypothesis is that increasing the pressure within the therapeutic focus causes fragmentation and cavitation inside the amorphic calcifications, leading to disorganization and disintegration of the deposit. The disappearance of the deposit may be due to breakthrough into the adjacent subacromial bursa or local resorptive reactions in the surrounding soft tissue.

Many authors have reported good results with low- or high-energy shock wave therapy in patients with calcifying tendinitis of the shoulder $[2,8,25,33,39]$. Rompe et al. [30] compared ESWT with conventional surgery in the treatment of calcifying tendinitis of the shoulder. These authors reported that surgery was superior to high-energy shock wave therapy for patients with homogeneous deposits. For patients with inhomogeneous deposits, highenergy ESWT was equivalent to surgery.

In the literature, minor complications of ESWT, such as pain in the shoulder, local soft tissue swelling, cutaneous erosions, erythema, and local subcutaneous hematomas have been reported [35]. Durst et al. reported one case of osteonecrosis of the humeral head after ESWT [4]. In vivo studies (on pig shoulder) have demonstrated that the energy needed to disintegrate a calcific deposit with fragments that are smaller than $1,000 \mu \mathrm{m}$ is $0.42 \mathrm{~mJ} / \mathrm{mm}^{2}$, and between 2,000 and 3,000 impulses are required [22]. Clinical trials confirm the therapeutic results after one or two sessions with at least 1,500/2,000 pulses and an energy of $0.04-0.30 \mathrm{~mJ} / \mathrm{mm}^{2}[3,16,29,39]$. In comparable shortterm results, the costs for operative treatment are 5-7 times higher than for ESWT. The greater trauma caused by an operative procedure leads to patients being off work for a longer period, with a higher social economic cost [9].

The purpose of the current study was to compare the effect of ESWT on calcific tendinitis with the effect of arthroscopic treatment. Patients treated with ESWT had similar results to those treated with arthroscopy. We found functional improvement and pain reduction in both groups in the UCLA rating system. Statistical analyses showed no significant differences in the two groups. We only found a difference between the strength values before the treatment in the two groups $(P=0.03)$, perhaps because there was a higher percentage $(41 \%)$ of males in the group treated with ESWT.

At 24 months of follow-up, the excellent or good results in the two groups were correlated with the complete or 
partial resorption of the calcific deposit. We are not able to explain the three good results in the ESWT group obtained without resorption of the calcific deposit. We can only note that these three patients underwent a long period (an average of 90 days, \pm 7 ) of various rehabilitation settings, and all had homogeneous calcific deposits. In group II, the patients underwent an average of three sessions of 1,500 impulse each, because we administered a low dose of ESWT (from 0.10 to $0.13 \mathrm{~mJ} / \mathrm{mm}^{2}$ ). This permitted us to administer ESWT without anesthesia, resulting in $70 \%$ of the patients reporting excellent/good results.

In conclusion:

- Arthroscopy and ESWT are effective in the treatment of calcifying tendinitis

- Once again, the results show the importance of complete removal of the calcium

- There was no clinical advantages of arthroscopy compared with low-energy shock-wave therapy

- Repeated low-energy sessions of ESWT are effective and can be administrated without anesthesia and hospitalization.

Based on these results, we think that ESWT should be considered before surgery in the treatment of patients with chronic calcifying tendinitis of the shoulder. Therefore, like surgical procedures, ESWT should be performed when an adequate conservative approach has failed. The patient should be informed about the pain involved in the treatment.

The present study has a series of weaknesses: the lack of a control group and the small numbers of cases in each group. Moreover, the patients were not randomized and the investigators were not blinded. The improvements in pain, function and strength are encouraging, but a longer term follow-up is necessary to determine whether our results are durable. Perhaps the most variable areas in published studies have been the dose of energy applied (low versus high energy), the number of treatments (one versus multiple), the need for anesthesia or sedation, and the total number of shocks applied. There are also still unanswered questions [20] about the application of ESWT. It is unclear which parameters may cause changes in tissues or in cell cultures, which tissues are damaged acutely or chronically, and whether the changes resolve.

Conflict of interest statement Each author certifies that he or she has no conflict of interest in connection with the submitted article.

\section{References}

1. Ark JW, Flock TJ, Flatow EL, Bigliani LU (1992) Arthroscopic treatment of calcific tendinitis of the shoulder. Arthroscopy $8(2): 183-188$
2. Cosentino R, De Stefano R, Selvi E, Frati E, Manca S, Frediani B, Marcolongo R (2003) Extracorporeal shock wave therapy for chronic calcific tendinitis of the shoulder: single blind study. Ann Rheum Dis 62(3):248-250

3. Daecke W, Kusnierczak D, Loew M (2002) Long-term effects of extracorporeal shockwave therapy in chronic calcific tendinitis of the shoulder. J Shoulder Elbow Surg 11(5):476-480

4. Durst HB, Blatter G, Kuster MS (2002) Osteonecrosis of the humeral head after extracorporeal shock-wave lithotripsy. J Bone Joint Surg Br 84-B(5):744-746

5. Ellman H, Gartsman GM (1993) Arthroscopic shoulder surgery and related procedures. Lea \& Febiger, Philadelphia, PA, pp 219-231

6. Gärtner J (1993) Tendinosis calcarea-results of treatment with needling. Z Orthop Ihre Grenzgeb 131(5):461-469

7. Gartsman GM (2003) Shoulder arthroscopy. Saunders, Philadelphia, PA, pp 266-270

8. Gerdesmeyer L, Wagenpfeil S, Haake M, Maier M, Loew M, Wortler K, Seil R, Handle G, Gassel S, Rompe JD (2003) Extracorporeal shock wave therapy for the treatment of chronic calcifying tendonitis of the rotator cuff: a randomized controlled trial. JAMA 290(19):2573-2580

9. Haake M, Rautmann M, Wirth T (2001) Assessment of the treatment costs of extracorporeal shock wave therapy versus surgical treatment for shoulder diseases. Int J Technol Assess Health Care 17(4):612-617

10. Hammer DS, Rupp S, Kreutz A, Pape D, Kohn D, Seil R (2002) Extracorporeal shockwave therapy (ESWT) in patients with chronic proximal plantar fasciitis. Foot Ankle Int 23(4):309-313

11. Harmon PH (1958) Methods and results in the treatment of 2, 580 painful shoulders, with special reference to calcific tendinitis and the frozen shoulder. Am J Surg 95(4):527-544

12. Jerosch J, Strauss JM, Schmiel S (1998) Arthroscopic treatment of calcific tendinitis of the shoulder. J Shoulder Elbow Surg $7(1): 30-37$

13. Lohr JF, Uhthoff HK (1996) Calcareous tendonitis. Orthopade 25(5):484-493

14. Loew M, Jurgowski W, Mau HC, Thomsen M (1995) Treatment of calcifying tendinitis of rotator cuff by extracorporeal shock waves: a preliminary report. J Shoulder Elbow Surg 4(2):101-106

15. Loew M, Rompe JD (1998) Stosswellenbehandlung bei orthopadischen Erkrankungen. Enke Verlag, Stuttgart, Germany, pp 8-9

16. Loew M, Daecke W, Kusnierczak D, Rahmanzadeh M, Ewerbeck V (1999) Shock-wave therapy is effective for chronic calcifying tendinitis of the shoulder. J Bone Joint Surg Br 81(5):863-867

17. Ludwig R, Mariotti G, Schlumpf U (1996) Prognosis of shoulder calcifications after irrigation treatment and roentgen findings. A prospective study and literature review. Schweiz Rundsch Med Prax 85(16):526-533

18. Maier M, Durr HR, Kohler S, Staupendahl D, Pfahler M, Refior HJ (2000) Analgesic effect of low energy extracorporeal shock waves in tendinosis calcarea, epicondylitis humeri radialis and plantar fasciitis. Z Orthop Ihre Grenzgeb 138(1):34-38 [Erratum in: Z Orthop Ihre Grenzgeb 2000, 138(2):185. Meier M (corrected to Maier M)]

19. Molè D, Kempf JF, Gleyze Rio B, Bonnomet F, Walch G (1993) Results of endoscopic treatment of non-broken tendinopathies of the rotator cuff. 2. Calcifications of the rotator cuff. Rev Chir Orthop Reparatrice Appar Mot 79(7):532-541

20. Ogden JA, Alvarez RG, Levitt R, Marlow M (2001) Shock wave therapy (Orthotripsy) in musculoskeletal disorders. Clin Orthop Relat Res 387:22-40

21. Ozkoc G, Akpinar S, Hersekli MA, Ozalay M, Tandogan RN (2002) Arthroscopic treatment of rotator cuff calcifying tendonitis. Acta Orthop Traumatol Turc 36(5):413-416

22. Perlick L, Korth O, Wallny T, Wagner U, Hesse A, Schmitt O (1999) The mechanical effects of shock waves in extracorporeal 
shock wave treatment of calcific tendinitis-an in vitro model. Z Orthop Ihre Grenzgeb 137(1):10-16

23. Pfister J, Gerber H (1997) Chronic calcifying tendinitis of the shoulder-therapy by percutaneous needle aspiration and lavage: a prospective open study of 62 shoulders. Clin Rheumatol 16(3):269-274

24. Re LP Jr, Karzel RP (1993) Management of rotator cuff calcifications. Orthop Clin North Am 24(1):125-132

25. Rompe JD, Rumler F, Hopf C, Nafe B, Heine J (1995) Extracorporeal shock wave therapy for calcifying tendinitis of the shoulder. Clin Orthop Relat Res 321:196-201

26. Rompe JD, Hopf C, Kullmer K, Heine J, Burger R (1996) Analgesic effect of extracorporeal shock-wave therapy on chronic tennis elbow. J Bone Joint Surg Br 78(2):233-237

27. Rompe JD, Hopf C, Nafe B, Burger R (1996) Low-energy extracorporeal shock wave therapy for painful heel: a prospective controlled single-blind study. Arch Orthop Trauma Surg 115(2):75-79

28. Rompe JD, Kirkpatrick CJ, Kullmer K, Schwitalle M, Krischnek O (1998) Dose-related effects of shock waves on rabbit tendo Achillis: a sonographic and histological study. J Bone Joint Surg Br 80-B:546-552

29. Rompe JD, Burger R, Hopf C, Eysel P (1998) Shoulder function after extracorporeal shock wave therapy for calcific tendinitis. J Shoulder Elbow Surg 7(5):505-509

30. Rompe JD, Zoellner J, Nafe B (2001) Shock wave therapy versus conventional surgery in the treatment of calcifying tendinitis of the shoulder. Clin Orthop Relat Res 387:72-82

31. Rubenthaler F, Ludwig J, Wiese M, Wittenberg RH (2003) Prospective randomized surgical treatments for calcifying tendinopathy. Clin Orthop Relat Res 410:278-284
32. Rupp S, Seil R, Kohn D (2000) Tendinosis calcarea of the rotator cuff. Orthopade 29(10):852-867

33. Seil R, Rupp S, Hammer DS, Ensslin S, Gebhardt T, Kohn D (1999) Extracorporeal shockwave therapy in tendionosis calcarea of the rotator cuff: comparison of different treatment protocols. Z Orthop Ihre Grenzgeb 137(4):310-315

34. Schleberger R, Senge T (1992) Non-invasive treatment of longbone pseudarthrosis by shock waves (ESWL). Arch Orthop Trauma Surg 111(4):224-227

35. Sistermann R, Katthagen BD (1998) Complications, side-effects and contraindications in the use of medium and high-energy extracorporeal shock waves in orthopedics. Z Orthop Ihre Grenzgeb 136(2):175-181

36. Snyder SJ (2003) Shoulder arthroscopy, 2nd edn. Lippincott Williams \& Wilkins, Philadelphia, PA, pp 284-293

37. Uthoff HK, Sarkar K, Maynard JA (1976) Calcifying tendinitis: a new concept of its pathogenesis. Clin Orthop Relat Res 118:164-168

38. Valchanou V, Michailov P (1991) High energy shock waves in the treatment of delayed and nonunion of fractures. Int Orthop 15(3): 181-184

39. Wang CJ, Ko JY, Chen HS (2001) Treatment of calcifying tendinitis of the shoulder with shock wave therapy. Clin Orthop Relat Res 387:83-89

40. Wittenberg RH, Rubenthaler F, Wolk T, Ludwig J, Willburger RE, Steffen R (2001) Surgical or conservative treatment for chronic rotator cuff calcifying tendinitis-a matched-pair analysis of 100 patients. Arch Orthop Trauma Surg 121(1-2):56-59 